\title{
Increased basal water and food ingestion in cingulectomized rats'
}

\author{
J. F. Labar and J. W. Wolfe \\ UNIVERSITY OF ROCHESTER
}

\begin{abstract}
Rats with anterior cingulate lesions showed a sustained mean increase of $22 \%$ in water ingestion. They also showed an immediate postoperative decrease of $30 \%$ in food intake followed by a prolonged elevation of $8 \%$. Sham operated, cortical control subjects, and normal animals did not show any changes in food or water ingestion.
\end{abstract}

\section{Problem}

Previous studies by McCleary (1961) and Kaada et al. (1962) have shown that rats and cats with septal lesions are deficient in inhibiting approach responses to food or water through which shock punishment is delivered. In contrast, lesions of the cingulate cortex do not disrupt such passive-avoidance behavior, and in cats produce a stronger avoidance response than that obtained from unoperated subjects (Lubar, 1964).

Because the passive avoidance of food or water involves the withholding of a consummatory response, it is important to determine whether the motivational state of animals is changed by the medial cortical lesions described above. There is recent evidence that rats with electrolytically placed septal lesions show increased water consumption and faster lever pressing for water reinforcement on CRF and FI operant schedules (Hunt \& Harvey, 1964). One could argue from this data that the passive-avoidance deficits in septal Ss arises from an increased thirst drive. However, if cingulectomized animals also show increases in food and water consumption, the hypothesis that medial cortical lesions produce changes in alimentary drive state consistent with their passive-avoidance performance would be less tenable than the response hypothesis proposed by McCleary (1961). We predicted that cingulate lesions would increase alimentary ingestion. This was based on observations that cingulectomized cats eat and drink more than do normal Ss during training in the passive-avoidance apparatus, prior to shock administration.

\section{Method}

The Ss were 17 Sprague-Dawley rats (380-460 gm), 120 days old at the beginning of the experiment. Ss were randomly subdivided into an experimental group of seven cingulectomized animals and a control group consisting of three sham operates, two cortical controls, and five normal controls. Each $\mathrm{S}$ was housed in an individual cage. The room temperature was maintained between $22^{\circ} \mathrm{C}-25.5^{\circ} \mathrm{C}$, and the humidity was kept constant. Ss were fed on an ad libitum ingestion schedule. Food consisted of a wet mash, 38\% Purina Micromix Rat Chow and $62 \%$ tap water, by weight, placed in ointment jars.
Water evaporation from the mash was negligible. Water was provided in $250 \mathrm{ml}$ stopped bottles attached to each cage, and was obtained by $\mathrm{S}$ through a metal spout. There was no problem with leakage.

Measurements of the quantities of water and food ingested were made at the same hour each day. These were begun several weeks after the animals had arrived in the laboratory and were taken for a minmum of from eight days preoperatively until the termination of the experiment, 48 days postoperatively. The procedure was was as follows: For water, each bottle was filled to a specified level, weighed to $0.5 \mathrm{gm}$, and attached to the S's cage. After 24 hours, it was weighed again, and the amount of water consumed was recorded. The bottle was then washed, refilled and replaced on the cage for the next day's measurement. Food consumption was measured in a similar fashion. In addition, each animal was weighed every two days.

Surgery was done aseptically by aspiration and was completed within an eight-day period. The anesthetic used was sodium pentobarbitol $(.08 \mathrm{cc} / 100 \mathrm{gm}$ body weight of $60 \mathrm{mg} / \mathrm{cc}$ solution Nembutal) supplemented by ether. Cingulate cortex was removed bilaterally, from $1.0 \mathrm{~mm}$ posterior to the bregma to the olfactory bulbs, without any interruption of the superior sagittal sinus. Cortical lesions were made laterally and were comparable to the cingulectomies in the amount of tissue removed. Sham operations consisted of bilateral dural incisions at the level of the anterior cingulate cortex. Subsequent histology revealed that none of the lesions invaded the septal area.

\section{Results}

The results are shown in Fig. 1. Amounts of water and food consumed are plotted in $\mathrm{ml}$ and gm per $100 \mathrm{gm}$ of body weight, respectively. These are more appropriate measures, due to weight differences among animals, than are total amounts ingested. The measurements of water ingested included measures of tap water from the bottles and water contained in the wet food mash. Similarly, the amount of food eaten was calculated on the basis of the amount of dry food contained in the wet mash. Compared to the control group, animals with cingulate lesions showed a rapid increase in daily water ingestion which reached a mean maximum of $32 \%$, two to three weeks postoperatively. Since the sham operated subjects and cortical controls showed no significant changes in either water or food ingestion postoperatively ( $p>.50$, Mann-Whitney U-test), their data was pooled with that of the normal controls. Throughout the 


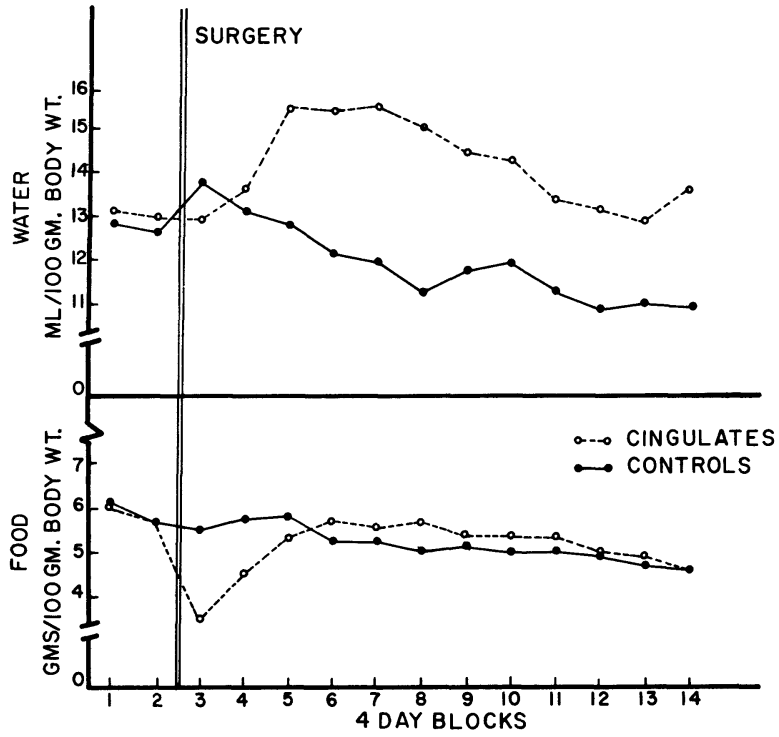

Fig. 1. Water and food ingestion in cingulectomized $(\mathrm{N}=7)$ and control animals (sham operates, cortical controls and normal animals, $\mathrm{N}=10$ ).

course of the experiment, the cingulate lesion and control groups showed parallel rates of change in water ingestion. The cingulate lesion group attained a mean increase in water ingestion of $22 \%$, over the entire postoperative period, compared with the controls. This increase is statistically significant resulting in a $U=7$; df, 7/10; $<$ <.01 (Mann-Whitney U-test, two-tail). Even 48 days postoperatively, these Ss were daily consuming $25 \%$ more water than the control groups. Furthermore, compared to their base preoperative levels, individual Ss with cingulate lesions showed maximal postoperative increases in water ingestion (over a single four-day period) ranging from $5.1 \%$ to $39 \%$, whereas the control group showed a slow and steady decrease in water intake (per 100 gm of body weight) compared to their base preoperative or initial levels. The small parallel decrease in water ingestion for both groups, during the course of the experiment, probably reflects an overall diminution of water consumed per unit body weight as Ss reached maturity. Significant differences in water ingestion between the cingulate and control groups cannot be attributed to differences in body weight between the two groups since the latter was not significantly different ( $p>.50$, Mann-Whitney U-test). Based on the evidence presented, we suggest that the effect of the cingulate lesion on water ingestion is long-term and perhaps permanent.

The cingulectomized Ss showed a marked postoperative depression (30\%) in food ingestion, coupled with a short term weight loss which reached a maximum of $3.5 \%$. Subsequently, there was an overall elevation in food intake of $8 \%$, compared with the control Ss, from days 13-44 postoperatively. This increase was significant $(p<.05$, Mann-Whitney U-test; $U=14 ; d f, 7 / 10$, two-tail). However, at the end of the experiment, both groups had reached the same level of food ingestion. It is possible that the long period of elevated food intake in the cingulate group may be compensatory for the immediate postoperative decrease in food intake.

\section{Diseussion}

These results clearly demonstrate that removal of the cingulate cortex causes an increase in drinking behavior comparable to that reported by Hunt \& Harvey (1964) for rats with septal lesions. At present there are no other published reports of increased eating or drinking as a result of cinulate lesions. Although there have been many studies of experimental hyperphagia and polydipsia resulting from selective hypothalamic stimulation and ablation (Brobeck, 1960), much less is known about extrahypothalamic regions which may control eating and drinking behavior. Nevertheless, Hayward \& Smith (1963) reported that stimulation of limbic regions including the hippocampus, olfactory tubercle and cingulate gyrus, activates the neurohypophysis and causes the release of $\mathrm{ADH}$. Perhaps cingulate lesions inhibit release of $\mathrm{ADH}$ thereby enhancing diuresis. In this case, increased water ingestion may be a compensatory reresponse for systemic water loss.

\section{Referenees}

BROBECK, J. R. Regulation of feeding and drinking. In Field, J. (Ed.), Handbook of Physiology, Vol. 2. Washington, D. C. American Physiological Assoc. 1960. Pp. 1197-1206.

HAYWARD, J. R., \& SMITH, W. K. Influence of limbic system on neurohypophysis. Arch. Neurol., 9, 1963, 171-177.

HUNT, H. F., \& HARVEY, J. A. The effect of septal lesions in the rat on water consumption and operant responding for water reinforcement. Paper delivered at the Eastern Psychological Assoc., April 18, 1964, Philadelphia, Pa.

KAADA, B. R., RASMUSSEN, E. W., \& KVEIM, O. Impaired acquisition of passive-avoidance behavior by subcallosal, septal, hypothalamic, and insular lesions in rats. J.comp. physiol. Psychol., 1962, 55, 661-670.

LUBAR, J. F. Effect of medial cortical lesions on the avoidance behavior of the cat. J. comp. physiol. Psychol., $1964,58,38-46$.

MCCLEARY, R. A. Response specificity in the behavioral effects of limbic system lesions in the cat. J. comp. physiol. Psychol., 1961, 54, 605-613.

\section{Note}

1. This research was supported in part by Grant MH10035-01 (Small Grants Program) from the National Institute of Mental Health, and by a USPHS Predoctoral Research Fellowship No. 1 FLMH-23, 100-01. We thank Lawrence F. Marshall, NSF Undergraduate Participation Fellow, No. 550-2-564, for his technical assistance. 